\section{Rosuvastatin Is Transferred into Human Breast Milk: A Case Report}

To the Editor:

Controversy exists on whether lactating women with familial hypercholesterolemia should resume statin treatment. This is partly due to the unavailability of data in humans regarding the transfer of statins into breast milk. Statin manufacturers advise against statin use for nursing mothers, referring to a study on rats indicating the transfer of atorvastatin via breast milk. ${ }^{1}$ It is generally accepted that statin levels of animal breast milk may not accurately reflect human breast milk levels. To our best knowledge, no published data are available on the transfer of 3-hydroxy-3methylglutaryl-coenzyme A reductase inhibitors via breast milk in humans.

\section{CASE SUMMARY}

We present a case of a 31-year-old white woman with familial hypercholesterolemia. Before pregnancy, her serum low-density lipoprotein cholesterol (LDL-C) level was 3.6 $\mathrm{mmol} / \mathrm{L}$ with chronic daily treatment of $40 \mathrm{mg}$ rosuvastatin (Crestor; AstraZeneca, Wilmington, DE) (Table). Statin use was stopped during pregnancy. It is known that LDL-C levels increase during pregnancy, and in this patient the LDL-C was $12.6 \mathrm{mmol} / \mathrm{L} 9$ days postpartum. Thirty-three days postpartum, a daily dose of $40 \mathrm{mg}$ rosuvastatin treatment was resumed.

Panel A in the Figure demonstrates the hourly increases in rosuvastatin concentrations in breast milk after oral ingestion, whereas panel $\mathrm{B}$ shows the breast milk concentrations on various days after initiation of

Funding: None.

Conflict of Interest: None.

Authorship: All authors had access to the data and a role in writing the manuscript.

Requests for reprints should be addressed to Aletta E. Schutte, PhD, Hypertension in Africa Research Team (HART), North-West University, Private Bag X6001, Potchefstroom 2531, South Africa.

E-mail address: Alta.Schutte@nwu.ac.za treatment. Rosuvastatin concentrations in breast milk increased steeply from hour 1 to 7 (ie, 15.2 to $29.4 \mathrm{ng} / \mathrm{mL}$ ) after oral intake, with a peak expected after approximately 10 hours. We obtained predominantly hindmilk samples on the days indicated in the Figure, panel B, but the foremilk-to-hindmilk ratio may be different for the hourly samples in panel A. Whether there are differences between fore- and hindmilk statin concentrations is unknown.

The breast milk concentrations ranged between 21.9 and $22.8 \mathrm{ng} / \mathrm{mL}$ over 3 test days (Figure, panel B) with sampling done 3, 3.8, or 21 hours after intake. Serum rosuvastatin concentration 23 hours after dose intake was lower than overall breast milk concentrations, namely, $18 \mathrm{ng} / \mathrm{mL}$.

\section{DISCUSSION}

Our case report presents the first human evidence for transferal of rosuvastatin into breast milk, confirming a study in rats. ${ }^{1}$ Breast milk rosuvastatin concentrations were higher than in serum $(22.4 \mathrm{vs} 18 \mathrm{ng} / \mathrm{mL})$ at $21-23$ hours after intake. We found clear dose-related hourly fluctuations in breast milk rosuvastatin concentrations, but further studies are needed to demonstrate 24-hour concentration curves.

Although these data add to our knowledge regarding statin transfer into breast milk, it does not provide information on the safety of statins for infants. Controversy exists on when statin treatment should be initiated in children of families with familial hypercholesterolemia. Rodenburg et $\mathrm{al}^{2}$ suggest the earlier the better, in line with the American Heart Association recommendation of $\geq 10$ years in males and at the onset of menses in females. ${ }^{3}$ Elahi et $\mathrm{al}^{4}$ found reduced cardiovascular risk in offspring of mice exposed to a high-fat diet and pravastatin during pregnancy and lactation.

Consequently, physicians are uncertain whether, when, and how to treat children with familial hypercholesterolemia. Potential benefits of early statin treatment are evident, but unless indicated otherwise, the possibility exists that

Table Serum Cholesterol Profile

\begin{tabular}{llccc}
\hline & Treatment & TC $(\mathrm{mmol} / \mathrm{L})$ & LDL-C $(\mathrm{mmol} / \mathrm{L})$ & $\mathrm{HDL}-\mathrm{C}(\mathrm{mmol} / \mathrm{L})$ \\
\hline 1 month before pregnancy & $40 \mathrm{mg}$ rosuvastatin & 5.8 & 3.6 & 1.6 \\
9 days postpartum & None & 14.6 & 12.6 & 1.4 \\
\hline
\end{tabular}

HDL-C = high-density lipoprotein cholesterol; LDL-C = low-density lipoprotein cholesterol; TC = total cholesterol. 


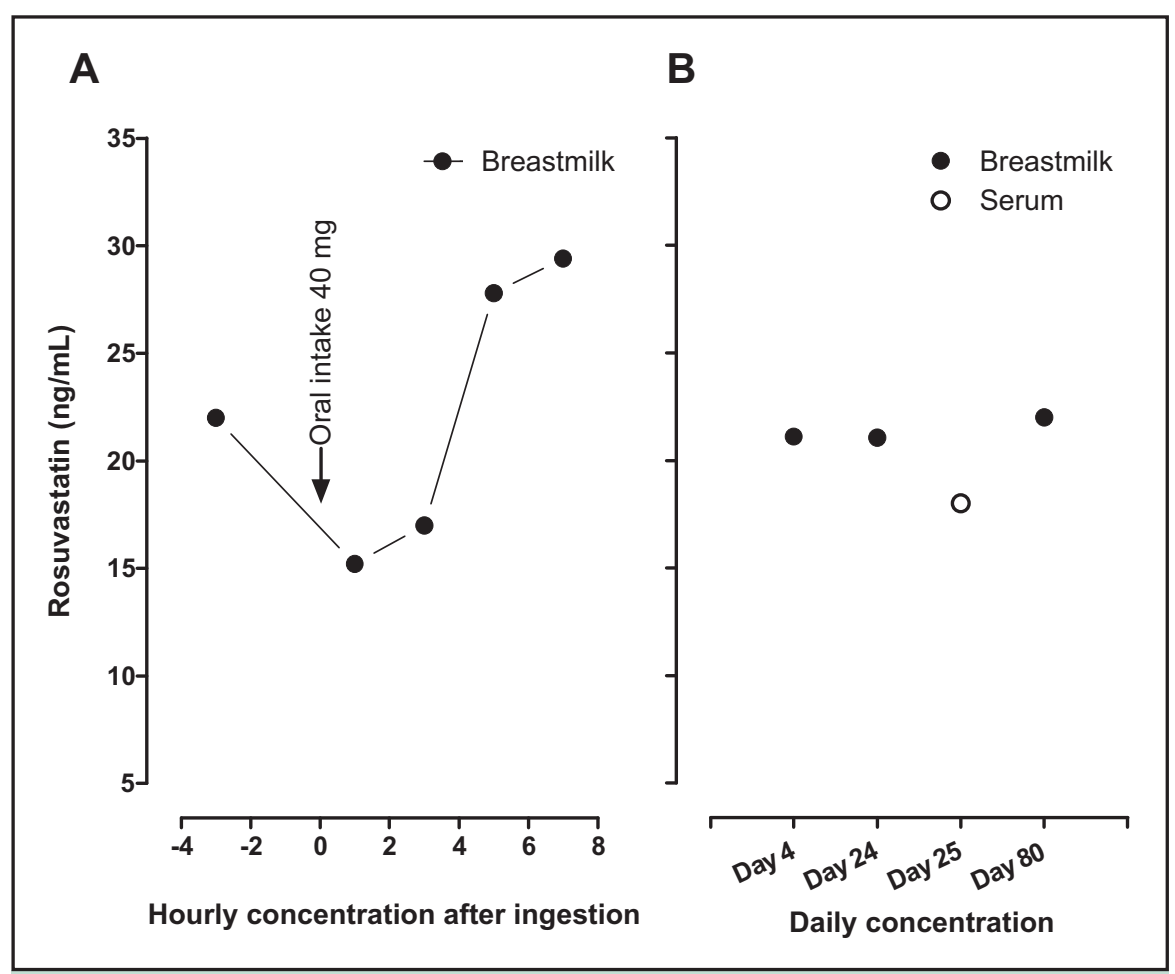

Figure (A) Hourly concentrations of rosuvastatin in breast milk after intake of a 40-mg dose. (Concentration at -3 hours: 21 hours after dose intake). (B) Breast milk and serum rosuvastatin concentrations on different days after initiation of treatment. (Day 4: 3 hours after dose intake; Day 24: 3.8 hours after dose intake; Day 25: 23 hours after dose intake; Day 80; 21 hours after dose intake).

hydroxy-3-methylglutaryl-coenzyme A reductase inhibitors transferred via breast milk may have a potential to cause serious adverse reactions in nursing infants.

\section{CONCLUSIONS}

Rosuvastatin transfers into human breast milk at high concentrations. After 21-23 hours, breast milk concentrations were approximately $4 \mathrm{ng} / \mathrm{mL}$ higher than in serum.

Aletta E. Schutte, $\mathrm{PhD}^{\mathrm{a}}$ Elizabeth A. Symington, MDiet ${ }^{\mathrm{b}}$

Jan L. du Preez, PhD $^{\mathrm{c}}$

${ }^{a}$ Hypertension in Africa Research Team (HART)

${ }^{c}$ Centre of Excellence for Pharmaceutical Sciences (Pharmacen)

North-West University

Potchefstroom, South Africa

\author{
${ }^{b}$ Department of Life and Consumer Sciences \\ University of South Africa \\ Pretoria, South Africa
}

http://dx.doi.org/10.1016/j.amjmed.2013.02.032

\section{References}

1. Henck JW, Craft WR, Black A, et al. Pre- and postnatal toxicity of the HMGCoA reductase inhibitor atorvastatin in rats. Toxicol Sci. 1998;41:88-99.

2. Rodenburg J, Vissers MN, Wiegman A, et al. Statin treatment in children with familial hypercholesterolemia: the younger, the better. Circulation. 2007;116:664-668.

3. McCrindle BW, Urbina EM, Dennison BA, et al. Summary of the American Heart Association's scientific statement on drug therapy of high-risk lipid abnormalities in children and adolescents. Arterioscler Thromb Vasc Biol. 2007;27:982-985.

4. Elahi MM, Cagampang FR, Anthony FW, et al. Statin treatment in hypercholesterolemic pregnant mice reduces cardiovascular risk factors in their offspring. Hypertension. 2008;51:939-944. 